\title{
$\beta$-Carotene and canthaxanthin alter the pro-oxidation and antioxidation balance in rats fed a high-cholesterol and high-fat diet
}

\author{
Chun-Kuang Shih ${ }^{1}$, Jui-Hung Chang ${ }^{1}$, Shwu-Huey Yang ${ }^{1}$, Tsui-Wei Chou ${ }^{2}$ and Hsing-Hsien Cheng ${ }^{1 *}$ \\ ${ }^{1}$ School of Nutrition and Health Sciences, Taipei Medical University, 250 Wu-Hsing Street, Taipei 110, Taiwan \\ ${ }^{2}$ Department of Tourism and Hospitality Management, Kainan University, 1 Kainan Road, Luzhu, Taoyuan County 33857, Taiwan
}

(Received 30 October 2006 - Revised 25 April 2007 - Accepted 31 May 2007)

This study investigated the effects of $\beta$-carotene and canthaxanthin on lipid peroxidation and antioxidative enzyme activities in rats fed a highcholesterol, high-fat diet. Wistar rats were divided into six groups. Negative control group (group NC) received a high-fat (150 g/kg) diet; cholesterol control group (group CC) received a high-cholesterol $(10 \mathrm{~g} / \mathrm{kg}$ ), high-fat diet. The other four groups were fed a high-cholesterol, high-fat diet supplemented with crystal $\beta$-carotene (group BC), $\beta$-carotene beadlet (group BB), canthaxanthin beadlet (group CX) or $\alpha$-tocopherol (group AT). Blood and livers were collected for analysis after 6 weeks of feeding. Group BB had significantly lower hepatic thiobarbituric acid reactive substance (TBARS) and conjugated diene concentrations, whereas group CX had a significantly lower plasma TBARS concentration than did group CC. In erythrocytes, glutathione peroxidase activities were significantly greater in groups BC, BB and CX than in group CC. Moreover, compared with group $\mathrm{CC}$, catalase activities were significantly greater in groups $\mathrm{BB}$ and $\mathrm{CX}$, and superoxide dismutase (SOD) activity was significantly greater in group BB. In livers, SOD activities were significantly greater in groups BC, BB and CX, and glutathione reductase activities were significantly greater in groups $\mathrm{BB}$ and $\mathrm{CX}$ than in group $\mathrm{CC}$. Compared with group $\mathrm{CC}$, hepatic retinol and $\alpha$-tocopherol concentrations were significantly greater in groups $\mathrm{BC}, \mathrm{BB}$ and $\mathrm{CX}$, whereas plasma and hepatic cholesterol concentrations were significantly lower in group BC. These findings suggest that $\beta$-carotene and canthaxanthin altered the pro-oxidation and antioxidation balance and suppressed cholesterol-induced oxidative stress via modulation of antioxidant system and cholesterol metabolism.

ß-Carotene: Canthaxanthin: Cholesterol: Pro-oxidation: Antioxidation

The generation of reactive oxygen species (ROS) and other free radicals during metabolism is an essential and normal process that is compensated for by the endogenous antioxidant defence system. Oxidative stress refers to a situation in which a significant imbalance exists between ROS as well as free radicals and the antioxidant defence system; thus, the accumulation of oxidative damage to molecules threatens the normal function of cells and organisms ${ }^{1,2}$. Oxidative stress has been shown to be related to CVD, cancer, diabetes mellitus and other chronic diseases that account for the leading causes of death in many countries. Hypercholesterolaemia is associated with increased ROS generation and oxidative stress $^{3,4}$, suggesting that cholesterol may play an important role in the development of several diseases. Numerous studies have indicated that dietary cholesterol exerts an apparent pro-oxidative effect on lipid peroxidation and lipoprotein oxidation $^{5-8}$. Therefore, it is plausible that antioxidants that inactivate ROS and protect against oxidative damage are thought to prevent cholesterol-induced oxidative stress.

Carotenoids belong to the tetraterpene family and comprise more than 600 known natural structural variants. Carotenoids are divided into two classes: non-polar carotenes (e.g. $\beta$-carotene and lycopene) containing only $\mathrm{C}$ and $\mathrm{H}$ atoms; polar xanthophylls (e.g. canthaxanthin and zeaxanthin) that carry at least one $\mathrm{O}$ atom ${ }^{9}$. The effects of carotenoids in human disease prevention have been widely reported. One of the mechanisms by which carotenoids act is their ability to modulate cell redox status $^{10}$. Someya et al. $^{11}$ reported that palm fruit carotene prevented UV ray-induced skin lipid peroxidation in mice. Iyama et al. ${ }^{12}$ reported that $\beta$-carotene suppressed carbon tetrachloride-induced lipid peroxidation in mice. Whittaker et al. ${ }^{13}$ evaluated the effects of dietary antioxidants on lipid peroxidation in rats with dietary $\mathrm{Fe}$ overload and found that the animals fed $\beta$ carotene plus $\alpha$-tocopherol had a lower level of lipid peroxidation. Kraus et al. ${ }^{14}$ showed that $\beta$-carotene decreased oxidative damage in erythrocytes from Zn-deficient rats. Palozza et al. ${ }^{10}$ found that canthaxanthin altered the protective ability of tissues against oxidative stress in mice. Riondel et al. ${ }^{15}$ indicated that $\beta$-carotene improved the antioxidant status of mice bearing lymphoid neoplasm. Nicolle et al. ${ }^{16}$ reported that carrot consumption improved the antioxidant status of cholesterol-fed rats.

The afore-mentioned studies suggest that carotenoids, alone or in combination with other nutrients, may function as potent antioxidants against oxidative stress induced by physical,

Abbreviations: BHT, butylated hydroxytoluene; GPX, glutathione peroxidase; GRD, glutathione reductase; ROS, reactive oxygen species; SOD, superoxide dismutase; TBARS, thiobarbituric acid reactive substance.

* Corresponding author: Professor Hsing-Hsien Cheng, fax +886 23770631, email chenghh@tmu.edu.tw 
chemical and biological factors. However, most of these carotenoid-related studies examined limited indices of lipid peroxidation or antioxidative enzyme activities. In addition, few studies have investigated the effect of carotenoids on cholesterol-induced oxidative stress. To evaluate the antioxidative potential of carotenoids on cholesterol-induced oxidative stress, the present study examined the effects of $\beta$-carotene (a non-polar carotenoid) and canthaxanthin (a polar carotenoid) on lipid peroxidation and antioxidative enzyme activities in rats fed a high-fat, high-cholesterol diet. $\alpha$-Tocopherol, a known antioxidant, was selected as a referential agent to evaluate the antioxidative potency of carotenoids.

\section{Materials and methods}

\section{Materials}

$\beta$-Carotene and canthaxanthin beadlets purchased from Hoffmann-La Roche (Basel, Switzerland) contained $10 \%$ $\beta$-carotene and $10 \%$ canthaxanthin. Crystal $\beta$-carotene, $\alpha$-tocopherol, cholic acid, DL-methionine and choline bitartrate were purchased from Sigma Chemical Co. (St. Louis, MO, USA). Cholesterol was purchased from Wako Pure Chemical Industries, Ltd. (Osaka, Japan). Maize flour was purchased from Roquette Freres (Lille, France). Soyabean oil was purchased from Uni-President Co. (Tainan, Taiwan). Casein, $\alpha$-cellulose, AIN-76 mineral mixture and AIN-76 vitamin mixture were purchased from ICN Biochemicals Co. (Costa Mesa, CA, USA).

\section{Animals and diets}

Seventy-two male Wistar rats were obtained at age 6 weeks from the Laboratory Animal Center of the College of Medicine at National Taiwan University (Taipei, Taiwan). They were housed individually in stainless wire-bottomed cages at a controlled temperature $\left(21 \pm 2^{\circ} \mathrm{C}\right)$, at a relative humidity of $50-70 \%$ and with a 12-h light-dark cycle. Animals were allowed free access to feed and water. All experimental diets were formulated on the basis of a modified AIN-76 $\operatorname{diet}{ }^{17,18}$. After 1 week of acclimatization, the animals were assigned to one of the six groups (twelve per group). The negative control group (group NC) received a high-fat $(150 \mathrm{~g} / \mathrm{kg})$ diet with no cholesterol supplementation and the cholesterol control group (group CC) received a high-fat, high-cholesterol $(10 \mathrm{~g} / \mathrm{kg})$ diet. The other four groups were fed a high-fat, high-cholesterol diet supplemented with crystal $\beta$-carotene (group BC), $\beta$-carotene beadlet (group BB), canthaxanthin beadlet (group $\mathrm{CX}$ ) or $\alpha$-tocopherol (group AT). Carotenoids and $\alpha$-tocopherol were both supplemented at a level of $2 \mathrm{~g} / \mathrm{kg}$. The composition of the experimental diets is shown in Table 1 . The study protocol was approved by the Institutional Animal Care and Use Committee of Taipei Medical University.

\section{Experimental procedures}

Animals were fed experimental diets for 6 weeks. Feed intake was recorded daily and body weight was recorded once per week. At the end of the experiment, the animals were anaesthetized with sodium pentobarbital $(1 \mathrm{~g} / \mathrm{kg}$ body
Table 1. Composition of the experimental diets $(\mathrm{g} / \mathrm{kg}$ diet) $\ddagger$

\begin{tabular}{lrrrrrr}
\hline & NC & CC & BC & BB & CX & AT \\
\hline Maize flour & 590 & 579 & 579 & 561 & 561 & 579 \\
Casein & 200 & 200 & 200 & 200 & 200 & 200 \\
Soybean oil & 150 & 150 & 148 & 148 & 148 & 148 \\
Cellulose & 10 & 10 & 10 & 10 & 10 & 10 \\
AIN-76 mineral mixture & 35 & 35 & 35 & 35 & 35 & 35 \\
AIN-76 vitamin mixture & 10 & 10 & 10 & 10 & 10 & 10 \\
DL-Methionine & 3 & 3 & 3 & 3 & 3 & 3 \\
Choline bitartrate & 2 & 2 & 2 & 2 & 2 & 2 \\
Cholesterol & - & 10 & 10 & 10 & 10 & 10 \\
Cholic acid & - & 1 & 1 & 1 & 1 & 1 \\
Crystal $\beta$-carotene & - & - & 2 & - & - & - \\
$\beta$-Carotene beadlet* & - & - & - & 20 & - & - \\
Canthaxanthin beadlet† & - & - & - & - & 20 & - \\
$\alpha$-Tocopherol & - & - & - & - & - & 2
\end{tabular}

${ }^{*}$ Contained $10 \% \beta$-carotene.

† Contained $10 \%$ canthaxanthin.

‡For details of diets and procedures, see Materials and methods.

NC, control diet without cholesterol; CC, $1 \%$ cholesterol diet; BC, $1 \%$ cholesterol diet with $0.2 \%$ crystal $\beta$-carotene; BB, $1 \%$ cholesterol diet with $0.2 \% \beta$-carotene as beadlet; CX, $1 \%$ cholesterol diet with $0.2 \%$ canthaxanthin as beadlet; AT, $1 \%$ cholesterol diet with $0.2 \% \alpha$-tocopherol.

weight) after being deprived of food for $12 \mathrm{~h}$. Blood was collected from the abdominal aorta, placed into heparinized tubes and centrifuged at $1800 \mathrm{~g}$ for $15 \mathrm{~min}$ to separate plasma from erythrocytes. Livers were dissected, rinsed in saline $(9 \mathrm{~g} / \mathrm{l})$ and weighed. All samples were stored at $-70^{\circ} \mathrm{C}$ until analysed.

\section{Carotenoids assay}

$\beta$-Carotene and canthaxanthin were analysed by HPLC according to our established method ${ }^{19,20}$. Aliquots of plasma $(1 \mathrm{ml})$ were mixed with $25 \mu \mathrm{l}$ trans- $\beta$-apo- $8^{\prime}$-carotenal solution $(0.4 \mathrm{mg} / \mathrm{l}$ methanol, internal standard) and $100 \mu \mathrm{l}$ absolute ethanol and denatured in $200 \mu$ l acetonitrile. Samples were extracted with $125 \mu \mathrm{l} n$-hexane and centrifuged at $13000 \mathrm{~g}$ under $4^{\circ} \mathrm{C}$ for $1 \mathrm{~min}$. Supernatants $(20 \mu \mathrm{l})$ were injected into a HPLC system (Hitachi L-6000 pump and L-4000 UV-VIS detector; Hitachi, Tokyo, Japan). Liver tissues $(0 \cdot 2 \mathrm{~g})$ were homogenized in $2 \mathrm{ml}$ absolute ethanol plus $0.5 \mu \mathrm{l}$ sodium ascorbate solution $(250 \mathrm{~g} / \mathrm{l})$ and saponified by adding saturated potassium hydroxide solution $(1 \mathrm{ml})$. After the addition of $\mathrm{NaCl}$ solution $(50 \mathrm{~g} / \mathrm{l}, 3 \mathrm{ml})$, samples were extracted with $5 \mathrm{ml} n$-hexane. The extracts were evaporated to dryness under $\mathrm{N}_{2}$ and dissolved in $1 \mathrm{ml}$ Sudan I solution $(0.3 \mathrm{mg} / \mathrm{l}$, internal standard). A $20-\mu l$ aliquot was injected into the HPLC system as stated earlier.

Chromatography was carried out with a Cosmosil C18 column $(4.6 \times 250 \mathrm{~mm}, 5 \mu \mathrm{m}$ particle size; Nacalai, Kyoto, Japan). The flow rate of mobile phase (methanol:toluene 3:1, $\mathrm{v} / \mathrm{v}$ ) was $1.5 \mathrm{ml} / \mathrm{min}$ and the concentration of carotenoid was measured from a standard curve detected at $470 \mathrm{~nm}$.

\section{Retinol assay}

Retinol was analysed by HPLC according to our established method $^{19,20}$. Aliquots of plasma $(250 \mu \mathrm{l})$ were mixed with $25 \mu \mathrm{l}$ all-trans-retinyl acetate solution $(16 \mathrm{mg} / \mathrm{l}$ ethanol, internal standard) and denatured in $100 \mu l$ acetonitrile. Samples were extracted with $125 \mu l n$-hexane, mixed with 
saturated potassium phosphate solution $(75 \mu \mathrm{l})$ and centrifuged at $13000 \mathrm{~g}$ at $4^{\circ} \mathrm{C}$ for $1 \mathrm{~min}$. Supernatant fractions $(20 \mu \mathrm{l})$ were injected into a HPLC system (Hitachi L-6000 pump and L-4000 UV-VIS detector; Hitachi). Liver tissues $(0 \cdot 1 \mathrm{~g})$ were homogenized in $2 \mathrm{ml}$ absolute ethanol containing pyrogallol $(30 \mathrm{~g} / \mathrm{l})$ and saponified by adding saturated potassium hydroxide solution $(1 \mathrm{ml})$. After the addition of $\mathrm{NaCl}$ solution $(50 \mathrm{~g} / \mathrm{l}, 3 \mathrm{ml})$, the samples were extracted with $5 \mathrm{ml}$ $n$-hexane. The extracts were evaporated to dryness under $\mathrm{N}_{2}$ and dissolved in $0.5 \mathrm{ml}$ all-trans-retinyl acetate solution $(40 \mathrm{mg} / \mathrm{l}$ ethanol, internal standard) and $5 \mathrm{ml}$ methanol. A 20- $\mu$ l aliquot was injected into the HPLC system as stated earlier. Chromatography was carried out with a Cosmosil C18 AR column $(4.6 \times 150 \mathrm{~mm}, 5 \mu \mathrm{m}$ particle size; Nacalai). The flow rate of mobile phase (methanol:0.5\% phosphate 97:3, $\mathrm{v} / \mathrm{v}, \mathrm{pH} 1.49$ ) was $1.0 \mathrm{ml} / \mathrm{min}$ and the concentration of retinol was measured from a standard curve detected at $325 \mathrm{~nm}$.

\section{$\alpha$-Tocopherol assay}

$\alpha$-Tocopherol was analysed by HPLC according to the method of Liu \& Huang ${ }^{21}$. Aliquots of plasma $(0.5 \mathrm{ml})$ were mixed with $2 \mathrm{ml}$ absolute ethanol containing pyrogallol (10 g/l), $0.1 \mathrm{ml} \mathrm{HCl}(12 \mathrm{~mol} / \mathrm{l})$ and $6 \mathrm{ml} n$-hexane containing butylated hydroxytoluene (BHT, $1.25 \mathrm{~g} / \mathrm{l})$. Extracts were evaporated to dryness under $\mathrm{N}_{2}$ and dissolved in $100 \mu \mathrm{l}$ methanol. A 20- $\mu \mathrm{l}$ aliquot was injected into a HPLC system (Hitachi L-6000 pump and L-4000 UV-VIS detector; Hitachi). Liver tissues were homogenized in phosphate buffer $(10 \mathrm{mmol} / \mathrm{l}, \mathrm{pH} 7 \cdot 4)$; the liver homogenate $(1 \mathrm{ml})$ was then deproteinated with $2 \mathrm{ml}$ absolute ethanol containing BHT $(10 \mathrm{~g} / \mathrm{l})$, saponified with saturated potassium hydroxide and extracted with $n$-hexane containing BHT $(1 \cdot 25 \mathrm{~g} / \mathrm{l})$. The extracts were evaporated to dryness under $\mathrm{N}_{2}$ and dissolved in $100 \mu \mathrm{l}$ methanol. A $20-\mu l$ aliquot was injected into the HPLC system as stated earlier. Chromatography was carried out with a Cosmosil C18 AR column $(4.6 \times 150 \mathrm{~mm}, 5 \mu \mathrm{m}$ particle size; Nacalai). The flow rate of mobile phase (methanol) was $1.0 \mathrm{ml} / \mathrm{min}$ and the concentration of $\alpha$-tocopherol was measured from a standard curve detected at $290 \mathrm{~nm}$.

\section{Lipid peroxidation}

Aliquots of liver were mixed with a solution of phosphate buffer $(10 \mathrm{mmol} / \mathrm{l}, \mathrm{pH} 7.4)$ and potassium chloride $(11.5 \mathrm{~g} / \mathrm{l})$, homogenized and centrifuged at $12000 \mathrm{~g}$ for $20 \mathrm{~min}$. Supernatant fractions (liver homogenates) were collected to determine lipid peroxidation. The assay of thiobarbituric acid reactive substance (TBARS) was based on the method of Yagi $^{22}$. Plasma or liver homogenates were mixed with TCA and centrifuged at $1500 \mathrm{~g}$ for $10 \mathrm{~min}$. Supernatant fractions were incubated with thiobarbituric acid and BHT solution at $95^{\circ} \mathrm{C}$ for $1 \mathrm{~h}$, mixed with butanol, and centrifuged at $1500 \mathrm{~g}$ for $10 \mathrm{~min}$. Supernatant fractions were measured with the use of fluorescent method emission at $553 \mathrm{~nm}$ with excitation at $515 \mathrm{~nm}$. The assay of conjugated dienes was based on the method of Banni et al. $^{23}$. Liver homogenates were mixed with an extraction reagent ( $n$-hexane:isopropanol 3:4, v/v) and centrifuged at $10000 \mathrm{~g}$ for $10 \mathrm{~min}$. The absorbance of supernatant fractions was measured at $234 \mathrm{~nm}$.

\section{Antioxidative enzyme activities}

Erythrocytes were washed with saline. The haemolysates were then prepared by diluting erythrocytes with double-distillated water and lysed in dry ice/acetone to ensure cell disruption ${ }^{24}$. Liver tissues were homogenized with EDTA $(1 \mathrm{mmol} / \mathrm{l})$ and Tris $(10 \mathrm{mmol} / \mathrm{l}, \mathrm{pH} 7.4)$ and centrifuged at $20000 \mathrm{~g}$ at $4^{\circ} \mathrm{C}$ for $5 \mathrm{~min}$. The upper layer was centrifuged at $105000 \mathrm{~g}$ at $4^{\circ} \mathrm{C}$ for $1 \mathrm{~h}$ and supernatant fractions (cytosolic fractions of livers) were collected for analyses of antioxidative enzyme activities. The assay of catalase activity was based on the method of $\mathrm{Luck}^{25}$. Erythrocyte haemolysates or liver homogenates were diluted with potassium phosphate buffer and mixed with hydrogen peroxide-potassium phosphate buffer. The absorbance was monitored at $240 \mathrm{~nm}$. The assay of superoxide dismutase (SOD) activity was based on the method of Beutler ${ }^{26}$ using a commercial kit (RANSOD kit; Randox Laboratories, Crumlin, Antrim, UK). Erythrocyte haemolysates or cytosolic fractions of liver were mixed with phosphate buffer, 2-(4-iodophenyl)-3-(4-nitrophenyl)-5-phenyl tetrazolium and xanthine oxidase. Absorbance was monitored at $505 \mathrm{~nm}$. The assay of glutathione peroxidase (GPX) activity was based on the method of Prohaska et al. ${ }^{27}$ and involved the use of a commercial kit (RANSEL kit; Randox Laboratories). Erythrocyte haemolysates or cytosolic fractions of liver were mixed with a reagent containing glutathione, glutathione reductase (GRD) and NADPH followed by the addition of cumene hydroperoxide. Absorbance was monitored at $340 \mathrm{~nm}$. The assay of GRD activity was based on the method of Bellomo et $a .^{28}$ and involved the use of a commercial kit (GRD kit; Randox Laboratories). Erythrocyte haemolysates or cytosolic fractions of liver were mixed with oxidized glutathione buffer and NADPH. Absorbance was monitored at $340 \mathrm{~nm}$. Protein concentrations were measured by the method of Lowry et al. ${ }^{29}$.

\section{Assays of cholesterol and TAG}

Serum cholesterol was measured by the method of Richmond $^{30}$. Serum TAG was measured by the method of McGowan et $a l .{ }^{31}$. Lipids in liver were extracted according to the method of Folch et al. ${ }^{32}$. Liver concentrations of cholesterol and TAG were analysed by the methods of Carlson \& Goldfarb $^{33}$ and Soloni et al. ${ }^{34}$, respectively.

\section{Statistical analysis}

Data are expressed as means and standard deviations. Differences in data between the experimental groups were assessed by one-way ANOVA with SAS software (SAS Institute, Cary, NC, USA). Means were considered significantly different at $P<0.05$ as determined by Duncan's multiple range test.

\section{Results}

The average initial and final body weights of rats were $250 \mathrm{~g}$ and $430 \mathrm{~g}$, respectively. During the 6-week experiment, the average weight gain of rats was $4 \mathrm{~g} / \mathrm{d}$. No significant differences in these weight-related variables were observed between the groups. Cholesterol feeding led to significantly higher relative liver weight and slightly but not significantly 
lower daily feed intake and higher feed efficiency; however, $\beta$-carotene, canthaxanthin and $\alpha$-tocopherol intakes did not alter these variables (Table 2).

Plasma and liver concentrations of $\beta$-carotene and canthaxanthin are shown in Table 3. $\beta$-Carotene was detected only in rats fed $\beta$-carotene (groups $\mathrm{BC}$ and $\mathrm{BB}$ ); canthaxanthin was detected only in rats fed canthaxanthin (group CX). Both plasma and hepatic $\beta$-carotene concentrations were higher $(P<0.05)$ in group $\mathrm{BB}$ than in group $\mathrm{BC}$.

Plasma and liver concentrations of retinol and $\alpha$-tocopherol are shown in Table 4 . The mean hepatic retinol concentration was significantly lower $(P<0.05)$ in group $\mathrm{CC}$ than in group NC. Groups BC and BB had significantly higher $(P<0.05)$ plasma and hepatic retinol concentrations than did group $\mathrm{CC}$, and the concentrations were similar to or higher than those of group NC. Groups CX and AT also had significantly higher $(P<0.05)$ hepatic retinol concentrations than did group $\mathrm{CC}$, but the concentrations were still lower than those of group NC. Plasma retinol concentrations were not affected by canthaxanthin or $\alpha$-tocopherol supplementation. The mean hepatic $\alpha$-tocopherol concentration was significantly lower $(P<0.05)$ in group $\mathrm{CC}$ than in group NC. Groups BC, BB, $\mathrm{CX}$ and AT had significantly higher $(P<0.05)$ hepatic $\alpha$-tocopherol concentrations than did group $\mathrm{CC}$. Furthermore, groups $\mathrm{BB}, \mathrm{CX}$ and AT had significantly higher $(P<0.05)$ plasma $\alpha-$ tocopherol concentrations than did group $\mathrm{CC}$.

As shown in Table 5, plasma and hepatic TBARS concentrations and hepatic conjugated diene concentrations were significantly higher $(P<0.05)$ in group $\mathrm{CC}$ than in group NC. Groups BC, BB, CX and AT had significantly lower $(P<0.05)$ hepatic TBARS concentrations than did group $\mathrm{CC}$, whereas groups $\mathrm{CX}$ and $\mathrm{AT}$ further decreased $(P<0.05)$ plasma TBARS concentrations. Hepatic conjugated diene concentrations were significantly lower $(P<0.05)$ in groups BB and AT than in group CC.

The antioxidative enzyme activities in rat erythrocytes are shown in Table 6. GPX activity was significantly lower $(P<0.05)$ in group $\mathrm{CC}$ than in group NC. However, catalase,

Table 2. Effects of $\beta$-carotene and canthaxanthin supplementation on daily feed intake, feed efficiency and relative liver weight in cholesterolfed ratsł

(Mean values and standard deviations for twelve rats per group)

\begin{tabular}{|c|c|c|c|c|c|c|}
\hline \multirow[b]{2}{*}{ Group } & \multicolumn{2}{|c|}{$\begin{array}{l}\text { Daily feed } \\
\text { intake }(\mathrm{g})\end{array}$} & \multicolumn{2}{|c|}{$\begin{array}{c}\text { Feed efficiency } \\
(\%)^{*}\end{array}$} & \multicolumn{2}{|c|}{$\begin{array}{l}\text { Relative liver } \\
\text { weight }(\%) \dagger\end{array}$} \\
\hline & Mean & $S D$ & Mean & $\mathrm{SD}$ & Mean & SD \\
\hline $\mathrm{NC}$ & $19 \cdot 7^{\mathrm{a}}$ & 0.4 & $20 \cdot 6^{b}$ & $3 \cdot 2$ & $2 \cdot 3^{b}$ & 0.2 \\
\hline $\mathrm{CC}$ & $19 \cdot 2^{\mathrm{ab}}$ & 1.0 & $21 \cdot 1^{\mathrm{ab}}$ & $2 \cdot 2$ & $5 \cdot 1^{a}$ & 0.5 \\
\hline $\mathrm{BC}$ & $19 \cdot 1^{\mathrm{ab}}$ & 0.6 & $23 \cdot 2^{\mathrm{ab}}$ & 3.6 & $4 \cdot 6^{\mathrm{a}}$ & 0.4 \\
\hline BB & $19 \cdot 0^{\mathrm{ab}}$ & 0.8 & $23.5^{\mathrm{ab}}$ & 4.4 & $5 \cdot 1^{\mathrm{a}}$ & 0.8 \\
\hline$c x$ & $19 \cdot 0^{\mathrm{ab}}$ & 0.5 & $22 \cdot 6^{\mathrm{ab}}$ & $3 \cdot 7$ & $4 \cdot 6^{\mathrm{a}}$ & 0.7 \\
\hline AT & $18 \cdot 8^{\mathrm{b}}$ & $1 \cdot 0$ & $24 \cdot 1^{a}$ & $2 \cdot 8$ & $4 \cdot 8^{a}$ & 0.4 \\
\hline
\end{tabular}

*Body weight gain/feed intake $\times 100 \%$.

† Liver weight/body weight $\times 100 \%$.

$\ddagger$ For details of diets and procedures, see Materials and methods.

$a, b$ Mean values within a column with unlike superscript letters are significantly different $(P<0.05)$.

NC, control diet without cholesterol; CC, $1 \%$ cholesterol diet; BC, $1 \%$ cholesterol diet with $0.2 \%$ crystal $\beta$-carotene; BB, $1 \%$ cholesterol diet with $0.2 \% \beta$-carotene as beadlet; CX, $1 \%$ cholesterol diet with $0.2 \%$ canthaxanthin as beadlet; AT, $1 \%$ cholesterol diet with $0.2 \% \alpha$-tocopherol.
Table 3. Effects of $\beta$-carotene and canthaxanthin supplementation on plasma and liver concentrations of $\beta$-carotene and canthaxanthin in cholesterol-fed rats $\dagger$

(Mean values and standard deviations for twelve rats per group)

\begin{tabular}{|c|c|c|c|c|c|c|c|c|}
\hline \multirow[b]{3}{*}{ Group } & \multicolumn{4}{|c|}{ Plasma } & \multicolumn{4}{|c|}{ Liver } \\
\hline & \multicolumn{2}{|c|}{$\begin{array}{c}\beta \text {-Carotene } \\
(\mathrm{nmol} / \mathrm{l})\end{array}$} & \multicolumn{2}{|c|}{$\begin{array}{l}\text { Canthaxanthin } \\
(\mathrm{nmol} / \mathrm{l})\end{array}$} & \multicolumn{2}{|c|}{$\begin{array}{c}\beta \text {-Carotene } \\
(\mu \mathrm{mol} / \mathrm{kg})\end{array}$} & \multicolumn{2}{|c|}{$\begin{array}{c}\text { Canthaxanthin } \\
(\mu \mathrm{mol} / \mathrm{kg})\end{array}$} \\
\hline & Mean & SD & Mean & $\mathrm{SD}$ & Mean & $\mathrm{SD}$ & Mean & SD \\
\hline $\mathrm{NC}$ & $-{ }^{*}$ & - & - & - & - & - & - & - \\
\hline $\mathrm{CC}$ & - & - & - & - & - & - & - & - \\
\hline $\mathrm{BC}$ & $39^{\mathrm{a}}$ & 10 & - & - & $58^{a}$ & 21 & - & - \\
\hline BB & $93^{b}$ & 15 & - & - & $221^{\mathrm{b}}$ & 172 & - & - \\
\hline$c x$ & - & - & 123 & 30 & - & - & 357 & 261 \\
\hline AT & - & - & - & - & - & - & - & - \\
\hline
\end{tabular}

${ }^{*}$ Not detectable.

$\dagger$ For details of diets and procedures, see Materials and methods.

${ }_{a, b}$ Mean values within a column with unlike superscript letters are significantly different $(P<0.05)$.

NC, control diet without cholesterol; CC, $1 \%$ cholesterol diet; BC, $1 \%$ cholesterol diet with $0.2 \%$ crystal $\beta$-carotene; BB, $1 \%$ cholesterol diet with $0.2 \% \beta$-carotene as beadlet; CX, $1 \%$ cholesterol diet with $0.2 \%$ canthaxanthin as beadlet; AT, $1 \%$ cholesterol diet with $0.2 \% \alpha$-tocopherol.

SOD and GRD activities were not affected significantly by cholesterol feeding. Groups BC, BB, CX and AT had significantly higher $(P<0.05)$ GPX activities than did group $\mathrm{CC}$, and the levels were similar to or higher than those of group NC. Groups BB and CX had significantly higher $(P<0.05)$ catalase activities than did the other groups. In addition, SOD activity was significantly higher $(P<0 \cdot 05)$ in group BB than in group CC. GRD activity was not affected significantly by $\beta$-carotene, canthaxanthin or $\alpha$-tocopherol supplementation.

The antioxidative enzyme activities in rat livers are shown in Table 7. SOD activity was significantly lower $(P<0 \cdot 05)$ and GRD activity was significantly higher $(P<0.05)$ in group CC than in group NC. However, catalase and GPX activities were not affected significantly by cholesterol feeding. Groups $\mathrm{BC}, \mathrm{BB}$ and $\mathrm{CX}$ had significantly higher $(P<0.05)$ SOD activities than did group CC, and the concentrations were similar to those of group NC. Group AT had a significantly higher $(P<0.05)$ catalase activity than did the other groups, except for group BB. Hepatic GPX activities were significantly lower $(P<0.05)$ in groups $\mathrm{BB}$ and $\mathrm{AT}$ than in group NC; however, the activities were not significantly different from those of group CC. Hepatic GRD activities were significantly higher $(P<0.05)$ in groups $\mathrm{BB}, \mathrm{CX}$ and AT than in group CC.

Cholesterol feeding resulted in significantly higher $(P<0 \cdot 05)$ plasma and liver cholesterol concentrations and significantly higher $(P<0 \cdot 05)$ liver TAG concentrations (Table 8$)$. Groups BC and BB had significantly lower $(P<0.05)$ plasma cholesterol concentrations than did group $\mathrm{CC}$, whereas group BC further decreased $(P<0.05)$ the hepatic cholesterol concentration. Group CX had significantly higher $(P<0.05)$ plasma TAG concentrations than did the other groups, except for group BC; however, hepatic TAG concentrations were not affected significantly by $\beta$-carotene, canthaxanthin or $\alpha$-tocopherol supplementation. 
Table 4. Effects of $\beta$-carotene and canthaxanthin supplementation on plasma and liver concentrations of retinol and $\alpha$-tocopherol in cholesterol-fed rats $^{\star}$

(Mean values and standard deviations for twelve rats per group)

\begin{tabular}{|c|c|c|c|c|c|c|c|c|}
\hline \multirow{2}{*}{ Group } & \multicolumn{4}{|c|}{ Plasma } & \multicolumn{4}{|c|}{ Liver } \\
\hline & \multicolumn{2}{|c|}{ Retinol $(\mu \mathrm{mol} / \mathrm{l})$} & \multicolumn{2}{|c|}{$\alpha$-Tocopherol $(\mu \mathrm{mol} / \mathrm{l})$} & \multicolumn{2}{|c|}{ Retinol (mol/kg) } & \multicolumn{2}{|c|}{$\alpha$-Tocopherol $(\mu \mathrm{mol} / \mathrm{kg})$} \\
\hline NC & $1.92^{\mathrm{ab}}$ & 0.33 & $0.39^{\mathrm{ab}}$ & 0.12 & $1 \cdot 12^{c}$ & 0.21 & $15 \cdot 0^{\mathrm{b}}$ & $2 \cdot 0$ \\
\hline $\mathrm{CC}$ & $1 \cdot 67^{\mathrm{a}}$ & 0.51 & $0.33^{a}$ & 0.09 & $0.11^{\mathrm{a}}$ & 0.07 & $4 \cdot 2^{\mathrm{a}}$ & $1 \cdot 7$ \\
\hline $\mathrm{BC}$ & $2 \cdot 18^{\mathrm{bc}}$ & 0.39 & $0.35^{\mathrm{ab}}$ & 0.02 & $1.03^{c}$ & 0.52 & $12 \cdot 8^{b}$ & 1.9 \\
\hline$C X$ & $1 \cdot 81^{\mathrm{a}}$ & 0.46 & $0.46^{\mathrm{b}}$ & 0.12 & $0.44^{\mathrm{b}}$ & 0.23 & $12 \cdot 0^{b}$ & $1 \cdot 3$ \\
\hline AT & $1.86^{\mathrm{ab}}$ & 0.40 & $0.72^{c}$ & 0.23 & $0.45^{\mathrm{b}}$ & $0 \cdot 12$ & $83.0^{c}$ & $25 \cdot 7$ \\
\hline
\end{tabular}

${ }^{*}$ For details of diets and procedures, see Materials and methods.

a,b,c Mean values within a column with unlike superscript letters are significantly different $(P<0.05)$.

NC, control diet without cholesterol; CC, $1 \%$ cholesterol diet; BC, $1 \%$ cholesterol diet with $0.2 \%$ crystal $\beta$-carotene; BB, $1 \%$ cholesterol diet with $0.2 \% \beta$-carotene as beadlet; CX, $1 \%$ cholesterol diet with $0.2 \%$ canthaxanthin as beadlet; AT, $1 \%$ cholesterol diet with $0.2 \% \alpha$-tocopherol.

\section{Discussion}

The physiological functions and side effects of cholesterol have been widely documented. Feeding rats a high level of cholesterol commonly results in a fatty liver characterized by greater live tissue weight and an abnormal macroscopic appearance ${ }^{24,35}$. The present study showed that administration of cholesterol caused a higher relative liver weight in rats (Table 2) attributed to the accumulation of cholesterol and TAG (Table 8). Furthermore, the nutritional status of vitamins A (retinol) and E ( $\alpha$-tocopherol) was poor in the cholesterolfed rats (Table 4).

Cholesterol feeding led to an imbalance between oxidation and antioxidation. Plasma and hepatic TBARS and hepatic conjugated diene concentrations were significantly elevated (Table 5), whereas GPX activity in erythrocytes and SOD activity in liver decreased significantly in the cholesterol-fed rats (Tables 6 and 7). The observed effects of dietary

Table 5. Effects of $\beta$-carotene and canthaxanthin supplementation on plasma and liver TBARS and liver conjugated diene concentrations in cholesterol-fed rats*

(Mean values and standard deviations for twelve rats per group)

\begin{tabular}{|c|c|c|c|c|c|c|}
\hline \multirow[b]{3}{*}{ Group } & \multicolumn{3}{|c|}{ Plasma } & \multicolumn{3}{|c|}{ Liver } \\
\hline & \multicolumn{2}{|c|}{ TBARS $(\mathrm{mmol} / \mathrm{l})$} & \multicolumn{2}{|c|}{$\begin{array}{l}\text { TBARS } \\
(\mathrm{mmol} / \mathrm{kg})\end{array}$} & \multicolumn{2}{|c|}{$\begin{array}{c}\text { Conjugated } \\
\text { diene }(\mathrm{mmol} / \mathrm{kg})\end{array}$} \\
\hline & Mean & SD & Mean & SD & Mean & SD \\
\hline $\mathrm{NC}$ & $0.60^{a b}$ & 0.21 & $7 \cdot 6^{\mathrm{a}}$ & $6 \cdot 4$ & $0.08^{a}$ & 0.02 \\
\hline $\mathrm{CC}$ & $0.80^{\mathrm{C}}$ & 0.15 & $97 \cdot 0^{\mathrm{d}}$ & $24 \cdot 0$ & $0.31^{d}$ & 0.11 \\
\hline $\mathrm{BC}$ & $0.65^{b c}$ & 0.29 & $75 \cdot 3^{c}$ & 33.1 & $0.25^{\mathrm{cd}}$ & 0.10 \\
\hline BB & $0.69^{b c}$ & 0.25 & $40 \cdot 1^{b}$ & $22 \cdot 8$ & $0 \cdot 20^{\mathrm{bc}}$ & 0.09 \\
\hline $\mathrm{CX}$ & $0.57^{\mathrm{ab}}$ & 0.23 & $74 \cdot 1^{\mathrm{c}}$ & 36.9 & $0.27^{\mathrm{cd}}$ & 0.11 \\
\hline AT & $0.42^{\mathrm{a}}$ & 0.19 & $15 \cdot 9^{a}$ & $12 \cdot 2$ & $0 \cdot 16^{\mathrm{b}}$ & 0.03 \\
\hline
\end{tabular}

* For details of diets and procedures, see Materials and methods.

a,b,c,d Mean values within a column with unlike superscript letters are significantly different $(P<0.05)$

NC, control diet without cholesterol; CC, $1 \%$ cholesterol diet; BC, $1 \%$ cholesterol diet with $0.2 \%$ crystal $\beta$-carotene; BB, $1 \%$ cholesterol diet with $0.2 \% \beta$-carotene as beadlet; $\mathrm{CX}, 1 \%$ cholesterol diet with $0.2 \%$ canthaxanthin as beadlet; AT, $1 \%$ cholesterol diet with $0.2 \% \alpha$-tocopherol; TBARS, thiobarbituric acid reactive substance. cholesterol on antioxidative enzyme activities in the present study were consistent with the findings of other studies ${ }^{24,36,37}$; however, the findings for lipid peroxidation were not consistent between studies. Tsai ${ }^{38}$ indicated that cholesterol feeding at levels of $1 \%$ or $1.5 \%$ elevated the rate of lipid oxidation in the liver of rats. Uysal et al. ${ }^{6}$ reported that cholesterol feeding at a level of $2 \%$ elevated hepatic lipid peroxide concentrations in rats. Aydemir et al. ${ }^{7}$ found that the plasma malondialdehyde concentration in rabbits fed cholesterol at a level of $1 \%$ was higher than that in rabbits fed no cholesterol. Balkan et al. $^{8}$ showed that rats fed a diet containing $2 \%$ cholesterol had higher plasma and liver lipid peroxide concentrations than did those fed no cholesterol. On the other hand, a few studies suggested that cholesterol has an antioxidative effect against oxidative stress by stabilizing membranes ${ }^{24,35}$. In these studies, the antioxidative effect of cholesterol was observed in rats fed a moderate-fat $(8 \%)$ diet containing $0.5 \%$ cholesterol compared with those fed a diet containing $0.05 \%$ cholesterol. It is possible that cholesterol has both pro-oxidative and antioxidative effects, depending on the

Table 6. Effects of $\beta$-carotene and canthaxanthin supplementation on antioxidative enzyme activities in erythrocytes of cholesterol-fed rats* (Mean values and standard deviations for twelve rats per group)

\begin{tabular}{|c|c|c|c|c|c|c|c|c|}
\hline \multirow[b]{2}{*}{ Group } & \multicolumn{2}{|c|}{$\begin{array}{l}\text { Catalase } \\
(\mathrm{U} / \mathrm{mg} \mathrm{Hb})\end{array}$} & \multicolumn{2}{|c|}{$\begin{array}{c}\text { SOD } \\
(\mathrm{U} / \mathrm{mg} \mathrm{Hb})\end{array}$} & \multicolumn{2}{|c|}{$\begin{array}{c}\text { GPX } \\
(\mathrm{U} / \mathrm{mg} \mathrm{Hb})\end{array}$} & \multicolumn{2}{|c|}{$\begin{array}{c}\text { GRD } \\
(\mathrm{mU} / \mathrm{mg} \mathrm{Hb})\end{array}$} \\
\hline & Mean & SD & Mean & SD & Mean & SD & Mean & SD \\
\hline $\mathrm{NC}$ & $15^{\mathrm{a}}$ & 4 & $1 \cdot 7^{\mathrm{ab}}$ & 0.3 & $0.55^{\mathrm{b}}$ & 0.07 & $0.13^{\mathrm{ab}}$ & 0.03 \\
\hline $\mathrm{CC}$ & $19^{a}$ & 8 & $1.4^{a}$ & 0.4 & $0.45^{\mathrm{a}}$ & 0.12 & $0.13^{\mathrm{ab}}$ & 0.04 \\
\hline $\mathrm{BC}$ & $23^{a}$ & 16 & $1 \cdot 8^{\mathrm{ab}}$ & 0.4 & $0.60^{b c}$ & 0.13 & $0.11^{\mathrm{ab}}$ & 0.06 \\
\hline BB & $40^{b}$ & 15 & $2 \cdot 0^{\mathrm{b}}$ & 0.6 & $0.66^{\mathrm{c}}$ & 0.03 & $0.14^{b}$ & 0.03 \\
\hline$c x$ & $35^{\mathrm{b}}$ & 18 & $1.5^{\mathrm{a}}$ & 0.4 & $0.59^{b c}$ & 0.07 & $0 \cdot 10^{\mathrm{a}}$ & 0.06 \\
\hline AT & $23^{a}$ & 11 & $1.5^{\mathrm{a}}$ & 0.5 & $0.57^{b}$ & 0.10 & $0 \cdot 13^{\mathrm{ab}}$ & 0.04 \\
\hline
\end{tabular}

${ }^{*}$ For details of diets and procedures, see Materials and methods.

${ }^{a, b, c}$ Mean values within a column with unlike superscript letters are significantly different $(P<0.05)$.

NC, control diet without cholesterol; CC, $1 \%$ cholesterol diet; BC, $1 \%$ cholesterol diet with $0.2 \%$ crystal $\beta$-carotene; BB, $1 \%$ cholesterol diet with $0.2 \% \beta$-carotene as beadlet; CX, $1 \%$ cholesterol diet with $0.2 \%$ canthaxanthin as beadlet; AT, $1 \%$ cholesterol diet with $0.2 \% \alpha$-tocopherol; SOD, superoxide dismutase; GPX, glutathione peroxidase; GRD, glutathione reductase. 
Table 7. Effects of $\beta$-carotene and canthaxanthin supplementation on antioxidative enzyme activities in livers of cholesterol-fed rats*

(Mean values and standard deviations for twelve rats per group)

\begin{tabular}{|c|c|c|c|c|c|c|c|c|}
\hline \multirow[b]{2}{*}{ Group } & \multicolumn{2}{|c|}{$\begin{array}{c}\text { Catalase } \\
\text { (U/mg } \\
\text { protein) }\end{array}$} & \multicolumn{2}{|c|}{$\begin{array}{c}\mathrm{SOD}(\mathrm{U} / \mathrm{mg} \\
\text { protein) }\end{array}$} & \multicolumn{2}{|c|}{$\begin{array}{l}\mathrm{GPX}(\mathrm{U} / \mathrm{mg} \\
\text { protein) }\end{array}$} & \multicolumn{2}{|c|}{$\begin{array}{c}\mathrm{GRD}(\mathrm{mU} / \mathrm{mg} \\
\text { protein) }\end{array}$} \\
\hline & Mean & SD & Mear & SD & lean & SD & Mean & SD \\
\hline C & $181^{\mathrm{ab}}$ & 23 & $4 \cdot 6^{b c}$ & 0.8 & $.40^{\mathrm{b}}$ & 0.0 & $0.58^{a}$ & 0.13 \\
\hline 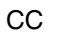 & $a^{a b}$ & 32 & $3 \cdot 8^{\mathrm{a}}$ & 0. & $.33^{\mathrm{ab}}$ & 0.1 & $0.70^{\mathrm{b}}$ & 0.13 \\
\hline $3 C$ & & 21 & $4 \cdot 6^{b c}$ & 0 & $\cdot 35^{\mathrm{ab}}$ & 0. & $0.75^{\mathrm{bc}}$ & 0.08 \\
\hline BB & $209^{b c}$ & 54 & $4 \cdot 6^{b c}$ & 0.7 & $0.30^{\mathrm{a}}$ & 0.07 & $0.81^{\mathrm{c}}$ & 0.06 \\
\hline$C X$ & $167^{\mathrm{a}}$ & 20 & $4 \cdot 9^{c}$ & 0.8 & $0.36^{a b}$ & 0.08 & $0.81^{\mathrm{c}}$ & 0.10 \\
\hline AT & $228^{c}$ & 46 & $4 \cdot 0^{\mathrm{ab}}$ & 0.9 & $0.32^{\mathrm{a}}$ & 0.07 & $0.80^{\mathrm{c}}$ & 0.08 \\
\hline
\end{tabular}

${ }^{*}$ For details of diets and procedures, see Materials and methods.

$\mathrm{a}, \mathrm{b}, \mathrm{c}$ Mean values within a column with unlike superscript letters are significantly different $(P<0.05)$.

NC, control diet without cholesterol; CC, $1 \%$ cholesterol diet; BC, $1 \%$ cholesterol diet with $0.2 \%$ crystal $\beta$-carotene; BB, $1 \%$ cholesterol diet with $0.2 \% \beta$-carotene as beadlet; $\mathrm{CX}, 1 \%$ cholesterol diet with $0.2 \%$ canthaxanthin as beadlet; AT, $1 \%$ cholesterol diet with $0.2 \% \alpha$-tocopherol; SOD, superoxide dismutase; GPX, glutathione peroxidase; GRD, glutathione reductase.

dietary conditions, such as cholesterol dose, the amount of fat and the fatty acid composition. Dietary fat containing high PUFA, such as soyabean oil and fish oil, plays a role in lipid peroxidation of tissues. In the present study, cholesterol exerted a pro-oxidative effect in rats fed a high-cholesterol (1\%), high-fat (15\% soyabean oil) diet.

Malondialdehyde is the principal product of PUFA peroxidation. Most assays used to measure malondialdehyde have been developed on the basis of its derivatization with thiobarbituric acid, so the result is often reported as TBARS ${ }^{39}$. TBARS is a common marker of lipid peroxidation. The peroxidation of PUFA is also accompanied by the formation of conjugated diene and it is another referential marker of lipid peroxidation $^{40}$. As expected, $\alpha$-tocopherol was a potent antioxidant; its intake resulted in a reduction in plasma and hepatic TBARS in rats fed cholesterol at levels similar to those of rats fed no cholesterol (Table 5). Furthermore, $\alpha$-tocopherol

Table 8. Effects of $\beta$-carotene and canthaxanthin on plasma and hepatic levels of cholesterol and TAG in cholesterol-fed rats*

(Mean values and standard deviations for twelve rats per group)

\begin{tabular}{|c|c|c|c|c|c|c|c|c|}
\hline \multirow[b]{3}{*}{ Group } & \multicolumn{4}{|c|}{ Plasma } & \multicolumn{4}{|c|}{ Liver } \\
\hline & \multicolumn{2}{|c|}{$\begin{array}{l}\text { Cholesterol } \\
(\mathrm{mmol} / \mathrm{l})\end{array}$} & \multicolumn{2}{|c|}{ TAG $(\mathrm{mmol} / \mathrm{l})$} & \multicolumn{2}{|c|}{$\begin{array}{l}\text { Cholesterol } \\
(\mathrm{mol} / \mathrm{kg})\end{array}$} & \multicolumn{2}{|c|}{$\begin{array}{c}\text { TAG } \\
(\mathrm{mmol} / \mathrm{kg})\end{array}$} \\
\hline & Mean & SD & Mean & SD & Mean & SD & Mean & SD \\
\hline $\mathrm{NC}$ & $1.83^{a}$ & 0.20 & $0.53^{\mathrm{a}}$ & 0.28 & $11^{a}$ & 2 & $28^{a}$ & 12 \\
\hline $\mathrm{CC}$ & $2 \cdot 67^{\mathrm{c}}$ & 0.53 & $0.54^{\mathrm{ab}}$ & 0.14 & $144^{c}$ & 13 & $89^{b}$ & 17 \\
\hline $\mathrm{BC}$ & $2 \cdot 09^{a b}$ & 0.52 & $0.69^{b c}$ & 0.20 & $132^{b}$ & 11 & $90^{\mathrm{b}}$ & 15 \\
\hline BB & $2 \cdot 21^{\mathrm{b}}$ & 0.22 & $0.45^{\mathrm{a}}$ & 0.10 & $139^{\mathrm{bc}}$ & 6 & $85^{b}$ & 22 \\
\hline $\mathrm{CX}$ & $2 \cdot 41^{b c}$ & 0.50 & $0.73^{c}$ & 0.11 & $141^{\mathrm{c}}$ & 10 & $83^{b}$ & 18 \\
\hline AT & $2 \cdot 45^{\mathrm{bc}}$ & 0.38 & $0.45^{\mathrm{a}}$ & 0.11 & $139^{\mathrm{bc}}$ & 8 & $92^{b}$ & 17 \\
\hline
\end{tabular}

* For details of diets and procedures, see Materials and methods.

$\mathrm{a}, \mathrm{b}, \mathrm{c}$ Mean values within a column with unlike superscript letters are significantly different $(P<0.05)$.

NC, control diet without cholesterol; CC, $1 \%$ cholesterol diet; BC, $1 \%$ cholesterol diet with $0.2 \%$ crystal $\beta$-carotene; BB, $1 \%$ cholesterol diet with $0.2 \% \beta$-carotene as beadlet; $\mathrm{CX}, 1 \%$ cholesterol diet with $0.2 \%$ canthaxanthin as beadlet; AT, $1 \%$ cholesterol diet with $0.2 \% \alpha$-tocopherol. also lowered the hepatic conjugated diene concentration of cholesterol-fed rats, although the concentration was still higher than that of rats fed no cholesterol (Table 5).

Carotenoids are believed to act as antioxidants by quenching singlet oxygen and scavenging peroxyl radicals ${ }^{9,41}$. In the present study, $\beta$-carotene (either crystal or beadlet form) and canthaxanthin intakes decreased hepatic TBARS concentrations in rats fed cholesterol and $\beta$-carotene beadlet or canthaxanthin intake further decreased hepatic conjugated diene and plasma TBARS concentrations (Table 5). These results suggest that both $\beta$-carotene and canthaxanthin have antioxidative activity and that $\beta$-carotene beadlet is effective in liver, whereas canthaxanthin is effective in plasma. The antioxidative capacity of carotenoids is dependent on their structure and the environment in which they exist ${ }^{42}$. Carotenoids are transported in the plasma of man and animals by lipoproteins. Non-polar carotenoids, such as $\beta$-carotene and lycopene, exist exclusively in the hydrophobic core of lipoproteins, which may not allow their transfer between lipoproteins at an appreciable rate, whereas polar carotenoids, such as canthaxanthin and zeaxanthin, exist mainly on the hydrophilic surface, resulting in a rapid surface transfer ${ }^{43,44}$. The lower plasma TBARS concentration in rats supplemented with canthaxanthin may be attributed to the antioxidative effect of canthaxanthin in the polar region of lipoproteins exposed to the aqueous plasma. Canthaxanthin was a more effective antioxidant than $\beta$-carotene in some in vitro studies ${ }^{45,46}$. However, the in vivo antioxidative potency of these two carotenoids has not been well studied due to the complexity of the biological system. In the present study, the antioxidative capacity of canthaxanthin was more potent in plasma than in liver, although the concentration of canthaxanthin was higher in liver than in plasma. It appears that the content (compared with the structure) of carotenoids in tissues plays a minor role in its antioxidative capacity.

Both catalase and GPX destroy $\mathrm{H}_{2} \mathrm{O}_{2}$ by converting it to $\mathrm{O}_{2}$ and water. The GPX/glutathione system is thought to be a major defence in low-level oxidative stress, whereas catalase is effective in high-level oxidative stress ${ }^{4}$. Despite a possible substitution by catalase in situations of moderate oxidative stress, GPX still appears to be the main antioxidative enzyme of the organism ${ }^{47}$. Erythrocytes are highly sensitive to oxidative stress because of their high concentrations of $\mathrm{Hb}$ and $\mathrm{O}_{2}{ }^{48}$. Even in erythrocytes that have a high content of catalase, $\mathrm{H}_{2} \mathrm{O}_{2}$ is essentially degraded by $\mathrm{GPX}^{49}$. The present study showed that the GPX activity of erythrocytes decreased in cholesterol-fed rats and recovered in rats supplemented with $\beta$-carotene, canthaxanthin or $\alpha$-tocopherol (Table 6). Furthermore, it appeared that $\beta$-carotene and canthaxanthin were more potent than was $\alpha$-tocopherol in enhancing GPX activity in erythrocytes. On the other hand, the catalase activities of erythrocytes increased in rats supplemented with the beadlet form of $\beta$-carotene and canthaxanthin. Low GPX activities have been shown to be an independent risk factor for cardiovascular events ${ }^{4}$. These results suggest that $\beta$-carotene and canthaxanthin may overcome the oxidative stress of erythrocytes induced by cholesterol and may prevent CVD.

SOD catalyses the one-electron dismutation of superoxide into $\mathrm{H}_{2} \mathrm{O}_{2}$ and $\mathrm{O}_{2}{ }^{49}$. When disease is present, an imbalance 
between the amount of superoxide formed and the ability of SOD to remove it (activity of the enzyme is decreased) exists. The consequence of this imbalance results in superoxide-mediated damage, such as lipid peroxidation ${ }^{50}$. Several animal models of diseases have shown that GM mice that lack SOD are more sensitive and those that over-express SOD are resistant to diseases ${ }^{50}$. In addition, preclinical studies have shown that SOD has a protective effect in animal models of diseases, such as ischaemia-reperfusion injury in the heart, liver and brain ${ }^{50}$. The present study showed that liver SOD activity decreased in cholesterol-fed rats and recovered in rats supplemented with $\beta$-carotene and canthaxanthin (Table 7); these findings suggest that these carotenoids may prevent superoxide-associated injury resulting from cholesterol by reducing oxidative stress in the liver.

Several lines of evidence suggest that carotenoids modify lipid metabolism. Amen \& Lachance ${ }^{51}$ reported that $\beta$-carotene intake decreased serum cholesterol in rats fed a vitamin A-deficient hypercholesterolaemic diet. Erdman \& Lachance ${ }^{52}$ reported that $\beta$-carotene decreased serum cholesterol in hypercholesterolaemic rats. Lopez \& Tsai ${ }^{53}$ indicated that canthaxanthin elevated serum total cholesterol and HDLcholesterol concentrations and decreased liver cholesterol concentrations in rats fed a cholesterol-enriched $(0.2 \%)$ diet. Murillo ${ }^{54}$ showed that both canthaxanthin and astaxanthin had a hypercholesterolaemic effect in rats. Our previous study found that $\beta$-carotene prevented both an increase in serum LDL-cholesterol and a decrease in serum HDL-cholesterol in rats fed $1 \%$ cholesterol $^{19}$. $\beta$-Carotene also showed anti-hyperlipidaemic effects in spontaneously hypertensive rats ${ }^{55,56}$. In the present study, dietary cholesterol $(1 \%)$ significantly elevated plasma and hepatic cholesterol concentrations, and $\beta$-carotene (especially crystal form) supplementation improved the higher plasma and hepatic cholesterol concentrations induced by cholesterol (Table 8). The plasma cholesterol concentration of group $\mathrm{BC}$ reached a level similar to that of group $\mathrm{NC}$; the hepatic cholesterol concentration of group BC was significantly lower than that of group $\mathrm{CC}$, although it was still much higher than that of group NC. It was previously shown that both dietary and serum cholesterol are closely related to $\mathrm{CVD}^{57,58}$. These results suggest that $\beta$-carotene may prevent CVD by modifying cholesterol metabolism. TAG metabolism was not affected by dietary carotenoids, except for canthaxanthin (Table 8). Plasma TAG concentrations increased after canthaxanthin supplementation (group CX). The meaning of this phenomenon remains to be investigated.

In conclusion, the present study showed that $\beta$-carotene and canthaxanthin supplementation had modulating effects on lipid peroxidation and antioxidative enzyme activities in rats fed a high-cholesterol, high-fat diet. $\beta$-Carotene beadlet significantly decreased hepatic TBARS and conjugated diene concentrations, and canthaxanthin significantly decreased plasma TBARS concentrations. Both GPX activity in erythrocytes and SOD activity in liver decreased with cholesterol feeding and recovered with $\beta$-carotene and canthaxanthin supplementation. These findings suggest that $\beta$-carotene and canthaxanthin altered the pro-oxidation and antioxidation balance and suppressed cholesterol-induced oxidative stress by modulating endogenously the antioxidant system and cholesterol metabolism.

\section{References}

1. Willcox JK, Ash SL \& Catignani GL (2004) Antioxidants and prevention of chronic disease. Crit Rev Food Sci Nutr 44, 275-295.

2. Blomhoff R (2005) Dietary antioxidants and cardiovascular disease. Curr Opin Lipidol 16, 47-54.

3. Griendling KK \& FitzGerald GA (2003) Oxidative stress and cardiovascular injury part II: animal and human studies. Circulation 108, 2034-2040.

4. Wassmann S, Wassmann K \& Nickenig G (2004) Modulation of oxidant and antioxidant enzyme expression and function in vascular cell. Hypertension 44, 381-386.

5. Tsai AC, Thie GM \& Lin CR (1977) Effect of cholesterol feeding on tissue lipid peroxidation, glutathione peroxidase activity and liver microsomal functions in rats and guinea pigs. $J$ Nutr 107, 310-319.

6. Uysal M, Kutalp G \& Seckin S (1988) The effect of cholesterol feeding on lipid peroxide, glutathione peroxidase and glutathione transferase in the liver of rats. Internat $J$ Vit Nutr Res 58, 339-342.

7. Aydemir EO, Duman C, Celik HA, Turgan N, Uysal A, Mutaf I, Habif S, Ozmen D, Nisli N \& Bayindir O (2000) Effects of defibrotide on aorta and brain malondialdehyde and antioxidants in cholesterol-induced atherosclerotic rabbits. Internat J Clin Lab Res 30, 101-107.

8. Balkan J, Dogru-Abbasoglu S, Aykac-Toker G \& Uysal M (2004) Serum pro-oxidant-antioxidant balance and low-density lipoprotein oxidation in healthy subjects with different cholesterol level. Clin Exp Med 3, 237-242.

9. Tapiero H, Townsend DM \& Tew KD (2004) The role of carotenoids in the prevention of human pathologies. Biomed Pharmacother 58, 100-110.

10. Palozza P, Calviello G, Emilia De Leo M, Serini S \& Bartoli GM (2000) Canthaxanthin supplementation alters antioxidant enzymes and iron concentration in liver of Balb/c mice. J Nutr 130, 1303-1308

11. Someya K, Totuska T, Murakoshi M, Kitano H \& Miyazawa T (1994) The effect of natural carotenoid (palm fruit carotene) intake on skin lipid peroxidation in hairless mice. J Nutr Sci Vitaminol 40, 303-314.

12. Iyama T, Takasuga A \& Azuma M (1996) Beta-carotene accumulation in mouse tissues and a protective role against lipid peroxidation. Internat J Vit Nutr Res 66, 301-305.

13. Whittaker P, Wamer WG, Chanderbhan RF \& Dunkel VC (1996) Effects of alpha-tocopherol and beta- carotene on hepatic lipid peroxidation and blood lipids in rats with dietary iron overload. Nutr Cancer 25, 119-128.

14. Kraus A, Roth HP \& Kirchgessner M (1997) Supplementation with vitamin $\mathrm{C}$, vitamin $\mathrm{E}$ or beta-carotene influences osmotic fragility and oxidative damage of erythrocytes of zinc-deficient rats. J Nutr 127, 1290-1296.

15. Riondel J, Wong HK, Glise D, Ducros V \& Favier A (2002) The effect of a water-dispersible beta-carotene formulation on the prevention of age-related lymphoid neoplasms in mice. Anticancer Res 22, 883-888.

16. Nicolle C, Cardinault N, Aprikian O, et al. (2003) Effect of carrot intake on cholesterol metabolism and on antioxidant status in cholesterol-fed rats. Eur J Nutr 42, 254-261.

17. American Institute of Nutrition (1977) Report of the American Institute of Nutrition ad hoc committee on standards for nutritional studies. J Nutr 107, 1340-1348.

18. American Institute of Nutrition (1980) Second report of the ad hoc committee on standards for nutritional studies. J Nutr 110, 1726.

19. Shih C-K, Cheng H-H \& Shieh M-J (1997) Effects of beta-carotene on lipid metabolism in rats fed with or without cholesterol. Nutr Sci J 22, 287-301. 
20. Cheng H-H, Guo D-C \& Shieh M-J (1999) Altered bioavailability of beta-carotene in rats fed diets containing cholesterol and soybean oil or lard. Food Sci Agric Chem 1, 237-243.

21. Liu J-F \& Huang C-J (1995) Tissue alpha-tocopherol retention in male rats is compromised by feeding diets containing oxidized frying oil. J Nutr 125, 3071-3080.

22. Yagi K (1987) Lipid peroxide and human disease. Chem Phys Lipids 45, 337-351.

23. Banni S, Salgo MG, Evans RW, Corongiu FP \& Lombardi B (1990) Conjugated diene and trans fatty acids in tissue lipids of rats fed an hepatocarcinogenic choline-devoid diet. Carcinogenesis 11, 2053-2057.

24. Yuan YV, Kitts DD \& Godin DV (1998) Variations in dietary fat and cholesterol intakes modify antioxidant status of SHR and WKY rats. $J$ Nutr 128, 1620-1630.

25. Luck H (1963) Catalase. In Methods of Enzymatic Analysis, pp. 885-888 [HU Bergmeyer, editor]. New York: Academic Press.

26. Beutler E (1975) Red Cell Metabolism: A Manual of Biochemical Methods. New York: Grune \& Stratton Inc.

27. Prohaska JR, Oh SH, Hoekstra WG \& Ganther HE (1977) Glutathione peroxidase: inhibition by cyanide and release of selenium. Biochem Biophys Res Commun 74, 64-71.

28. Bellomo G, Mirabelli F, DiMonte D, Richelmi P, Thor H, Orrenius C \& Orrenius S (1987) Formation and reduction of glutathione-protein mixed disulfides during oxidative stress. A study with isolated hepatocytes and menadione (2-methyl1,4-naphthoquinone). Biochem Pharmacol 36, 1313-1320.

29. Lowry OH, Rosebrough NJ, Farr AL \& Randall RJ (1951) Protein measurement with folin phenol reagent. J Biol Chem 193, 265-275.

30. Richmond W (1973) Preparation and properties of a cholesterol oxidase from Nocardia sp. and its application to the enzymatic assay of total cholesterol in serum. Clin Chem 19, 1350-1356.

31. McGowan MW, Artiss JD, Strandbergh DR \& Zak B (1983) A peroxidase-coupled method for the colorimetric determination of serum triglycerides. Clin Chem 29, 538-542.

32. Folch J, Lees M \& Sloane-Stanley GH (1957) A simple method for the isolation and purification of total lipids from animal tissues. J Biol Chem 226, 497-509.

33. Carlson SE \& Goldfarb S (1977) A sensitive enzymatic method for determination of free and esterified tissue cholesterol. Clinica Chim Acta 79, 575-582.

34. Soloni FG (1971) Simplified manual micromethod for determination of serum triglycerides. Clin Chem 17, 529-534.

35. Yuan YV \& Kitts DD (2002) Dietary source and cholesterol interactions alter plasma lipids and tissue susceptibility to oxidation in spontaneously hypertensive (SHR) and normotensive Wistar Kyoto (WKY) rats. Mol Cell Biochem 232, 33-47.

36. Lu YF \& Chiang CF (2001) Effect of dietary cholesterol and fat levels on lipid peroxidation and the activities of antioxidant enzymes in rats. Internat J Vit Nutr Res 71, 339-346.

37. Yuan YV \& Kitts DD (2003) Dietary n-3 fat and cholesterol alter tissue antioxidant enzymes and susceptibility to oxidation in SHR and WKY rats. J Nutr 133, 679-688.

38. Tsai AC (1975) Lipid peroxidation and glutathione peroxidase activity in the liver of cholesterol-fed rats. J Nutr 105, 646-951.

39. Del Rio D, Stewart AJ \& Pellegrini N (2005) A review of recent studies on malondialdehyde as toxic molecule and biological marker of oxidative stress. Nutr Metab Cardiovasc Dis 15, 316-328.

40. Meagher EA \& FitzGerald GA (2000) Indices of lipid peroxidation in vivo: strengths and limitations. Free Radic Biol Med 28, 1745-1750.

41. Palozza P \& Krinsky NI (1992) Antioxidant effects of carotenoids in vitro and in vivo: an overview. Methods Enzymol 213, 403-420.

42. El-Agamey A, Lowe GM, McGarvey DJ, Mortensen A, Phillip DM, Truscott TG \& Young AJ (2004) Carotenoid radical chemistry and antioxidant-pro-oxidant properties. Arch Biochem Biophys 430, 37-48.

43. Parker RS (1996) Absorption, metabolism, and transport of carotenoids. FASEB J 10, 542-551.

44. Yeum K-J \& Russell RM (2002) Carotenoid bioavailability and bioconversion. Апnи Rev Nutr 22, 483-504.

45. Terao J (1989) Antioxidant activity of beta-carotene-related carotenoids in solution. Lipids 24, 659-661.

46. Palozza P, Luberto C, Ricci P, Sgarlata E, Calviello G \& Bartoli GM (1996) Effect of beta-carotene and canthaxanthin on tertbutyl hydroperoxide-induced lipid peroxidation in murine normal and tumor thymocytes. Arch Biochem Biophys 325, $145-151$.

47. Brigelius-Flohe R (1999) Tissue-specific functions of individual glutathione peroxidases. Free Radic Biol Med 27, 951-965.

48. Eder K, Flader D, Hirche F \& Brandsch C (2002) Excess dietary vitamin $\mathrm{E}$ lowers the activities of antioxidative enzymes in erythrocytes of rats fed salmon oil. J Nutr 132, 3400-3404.

49. Chaudiere J \& Ferrari-Iliou R (1999) Intracellular antioxidants: from chemical to biochemical mechanisms. Food Chem Toxicol 37, 949-962.

50. Muscoli C, Cuzzocrea S, Riley DP, Zweier JL, Thiemermann C, Wang Z-Q \& Salvemini D (2003) On the selectivity of superoxide dismutase mimetics and its importance in pharmacological studies. Brit J Pharmacol 140, 445-460.

51. Amen RJ \& Lachance PA (1974) The effects of beta-carotene and canthaxanthin on serum cholesterol levels in the rats. Nutr Rep Int 10, 269-276.

52. Erdman JW \& Lachance PA (1974) Failure of the non-vitamin A active carotenoid lycopene to act as an antihypercholesterolemic agent in rats. Nutr Rep Int 10, 277-284.

53. Lopez SV \& Tsai AC (1992) Effects of dietary beta-carotene and canthaxanthin on lipid levels in rats. FASEB $J$ 6, A966.

54. Murillo E (1992) Hypercholesterolemic effect of canthaxanthin and astaxanthin in rats. Arch Latinoam Nutr 42, 409-413.

55. Tsai AC \& Mazeedi HA (1988) Effects of beta-carotene supplementation on serum lipid levels in spontaneously hypertensive (SH) rats. FASEB $J \mathbf{2}$, A854.

56. Tsai AC, Mazeedi HA \& Mameesh MS (1992) Dietary betacarotene reduces serum lipid concentration in spontaneously hypertensive rats fed a vitamin A-fortified and cholesterolenriched diet. J Nutr 122, 1768-1771.

57. Grundy SM (1990) Cholesterol and coronary heart disease: future directions. JAMA 264, 3053-3059.

58. Manninen V, Tenkanen L, Koskinen P, Huttunen JK, Manttari M, Heinonen OP \& Frick MH (1992) Joint effects of serum triacylglycerol and LDL cholesterol and HDL cholesterol concentration on coronary heart disease risk in the Helsinki Heart Study. Circulation 85, 37-45. 